\title{
Study of soil aggregate breakdown dynamics under low dispersive ultrasonic energies with sedimentation and $\mathrm{X}$-ray attenuation**
}

\author{
Jasmin Schomakers ${ }^{1 *}$, Franz Zehetner ${ }^{1}$, Axel Mentler ${ }^{1}$, Franz $_{\text {Ottner }}{ }^{2}$, and Herwig Mayer ${ }^{3}$ \\ ${ }^{1}$ Department of Forest and Soil Sciences, Institute of Soil Research, University of Natural Resources and Life Sciences, \\ Peter-Jordan-Str. 82, 1190 Vienna, Austria \\ ${ }^{2}$ Department of Civil Engineering and Natural Hazards, Institute of Applied Geology, University of Natural Resources and Life \\ Sciences, Peter-Jordan-Str. 70, 1190 Vienna, Austria \\ ${ }^{3}$ Department of Material Sciences and Process Engineering, Institute of Physics and Material Sciences, University of Natural \\ Resources and Life Sciences, Peter-Jordan-Str. 82, 1190 Vienna, Austria
}

Received May 4, 2015; accepted October 15, 2015

\begin{abstract}
A b s t r a c t. It has been increasingly recognized that soil organic matter stabilization is strongly controlled by physical binding within soil aggregates. It is therefore essential to measure soil aggregate stability reliably over a wide range of disruptive energies and different aggregate sizes. To this end, we tested highaccuracy ultrasonic dispersion in combination with subsequent sedimentation and X-ray attenuation. Three arable topsoils (notillage) from Central Europe were subjected to ultrasound at four different specific energy levels: $0.5,6.7,100$ and $500 \mathrm{~J} \mathrm{~cm}^{-3}$, and the resulting suspensions were analyzed for aggregate size distribution by wet sieving $(2000-63 \mu \mathrm{m})$ and sedimentation/X-ray attenuation (63-2 $\mu \mathrm{m})$. The combination of wet sieving and sedimentation technique allowed for a continuous analysis, at high resolution, of soil aggregate breakdown dynamics after defined energy inputs. Our results show that aggregate size distribution strongly varied with sonication energy input and soil type. The strongest effects were observed in the range of low specific energies $\left(<10 \mathrm{~J} \mathrm{~cm}^{-3}\right)$, which previous studies have largely neglected. This shows that low ultrasonic energies are required to capture the full range of aggregate stability and release of soil organic matter upon aggregate breakdown.

K e y w o r d s: aggregate size distribution, aggregate stability, sedigraph, ultrasound, soil organic matter
\end{abstract}

\section{INTRODUCTION}

Soil aggregates are widely studied to address various questions regarding soil organic matter (SOM) dynamics and nutrient cycling. Aggregation is perceived as an indicator of soil stability and erodibility (Bryan, 1971; Morgan,

*Corresponding author e-mail: jasmin.schomakers@boku.ac.at **This research was supported by the Austrian Science Fund (FWF): I 1396-B16, 2013-2016.
2005), and soil aggregates are of particular importance for processes of soil carbon sequestration (Chenu and Plante, 2006; Six et al., 2000).

Microaggregates $(250-20 \mu \mathrm{m})$ were studied early by Edwards and Bremner (1967b) who propozed a microaggregate theory which Tisdall and Oades (1982) developed further into the aggregate hierarchy theory. Microaggregates are held together by persistent binding agents and SOM is predominantly stabilized in stable microaggregates (Six et al., 2004) .

A variety of methods are used to assess the stability of soil aggregates. Ultrasonic equipment has been commonly used to study the breakdown of soil into smaller aggregates and particles (Kaiser et al., 2012; Raine, 1998; Schmidt et al., 1999). According to the aggregate hierarchy theory, breakdown occurs when sufficient mechanical stresses are applied to overcome the attractive forces within the aggregates (Raine, 1998).

Sedimentation techniques have been well established for soil science purposes (Gerzabek, 1992; Buchan et al., 1993; Goossens, 2008). Leifeld and Kögel-Knabner (2003) used ultrasonic treatment in combination with X-ray attenuation to determine the size distribution of microaggregates $(63-0.2 \mu \mathrm{m})$. They subjected their soil samples to ultrasound at 22 and $52 \mathrm{~J} \mathrm{~cm}^{-3}$, which destroyed most of the aggregates $>63 \mu \mathrm{m}$. Balesdent et al. (1991) and Amelung and Zech (1999) found physical damage of organic particles and redistribution of organic carbon among aggregate size classes starting at 60 and $90 \mathrm{~J} \mathrm{~cm}^{-3}$, respectively. Pronk

(C) 2015 Institute of Agrophysics, Polish Academy of Sciences 
T a b l e 1. Characterization of the topsoil $(0-10 \mathrm{~cm})$ samples

\begin{tabular}{|c|c|c|c|c|c|c|c|c|c|}
\hline \multirow{2}{*}{ Site } & Sand & Silt & Clay & $\mathrm{C}_{\text {org }}$ & $\mathrm{CaCO}_{3}$ & \multirow{2}{*}{$\mathrm{C} / \mathrm{N}$} & \multirow{2}{*}{$\begin{array}{c}\mathrm{EC} \\
\left(\mu \mathrm{S} \mathrm{cm}^{-1}\right)\end{array}$} & \multirow{2}{*}{$\begin{array}{c}\mathrm{pH} \\
\text { (in } \mathrm{CaCl}_{2} \text { ) }\end{array}$} & \multirow{2}{*}{$\begin{array}{l}\text { SAS } \\
(\%)\end{array}$} \\
\hline & & & $(\%)$ & & & & & & \\
\hline $\mathrm{a}$ & 53 & 33 & 14 & 1.73 & $<0.5$ & 16 & 266 & 5.7 & 42 \\
\hline $\mathrm{b}$ & 11 & 39 & 50 & 3.33 & 1.4 & 13 & 195 & 7.2 & 76 \\
\hline $\mathrm{c}$ & 24 & 65 & 12 & 1.86 & 17.9 & 13 & 173 & 7.3 & 23 \\
\hline
\end{tabular}

T a b l e 2. Semi-quantitative clay mineral analysis

\begin{tabular}{ccccccc}
\hline Site & Smectite & Vermiculite & Illite & Kaolinite & Chlorite & Mixed layer \\
\hline a & 17 & 8 & 48 & 24 & 3 & 6 \\
b & 44 & 16 & 29 & 6 & 10 & 10 \\
c & 20 & 11 & 49 & traces & traces \\
\hline
\end{tabular}

et al. (2011), on the other hand, showed that specific energy levels $\leq 800 \mathrm{~J} \mathrm{~cm}^{-3}$ were not sufficient to fully disperse aggregates $<63 \mu \mathrm{m}$. In their study, Pronk et al. (2011) did not detect any significant changes in particle size distribution at different ultrasonic energy levels from 100 to $800 \mathrm{~J} \mathrm{~cm}^{-3}$. By contrast, our study focused on low ultrasonic energies $<10 \mathrm{~J} \mathrm{~cm}^{-3}$ which to date have largely been neglected in the study of soil aggregate breakdown dynamics. Ultrasonic power used in most experiments is too large to differentiate stability, especially of weakly aggregated soils. In our study, the ultrasonic vibration amplitudes used are about one order of magnitude smaller than those of commercially available ultrasonic equipment, allowing us to study the gradual breakdown of soil aggregates. In combination with the sedimentation technique, our research aimed to characterize aggregate breakdown dynamics (2000-2 $\mu \mathrm{m})$ at high resolution after defined energy inputs.

\section{MATERIAL AND METHODS}

Three contrasting topsoil samples (Table 1) from agricultural fields in Austria were chosen for the study. These were selected from a number of samples collected from no-tillage sites of previous studies (Klik et al., 2010). All samples were air-dried and sieved through a $2 \mathrm{~mm}$ sieve to eliminate gravel and large organic debris. The soils were characterized according to the World Reference Base for Soil Resources (WRB, 2006), as follows:

a) a loamy sand Cambisol from Kirchberg am Walde ( $48^{\circ} 16^{\prime} \mathrm{N}$ and $\left.15^{\circ} 58^{\prime} \mathrm{E}\right)$;

b) a clay loam Cambisol from Tulln $\left(48^{\circ} 18^{\prime} \mathrm{N}\right.$ and $\left.16^{\circ} 02^{\prime} \mathrm{E}\right)$;

c) degraded silt loam Chernozem from Pixendorf $\left(48^{\circ} 16^{\prime} \mathrm{N}\right.$ and $15^{\circ} 58^{\prime} \mathrm{E}$ ).

Particle size distribution (Table 1) was conducted according to ISO 11277 (2009). This procedure involved a combination of sieving and sedimentation, of which the Köhn pipette is the standard procedure for sedimentation.
Total soil carbon was determined by combustion (ISO 10694, 2009), and soil inorganic carbon was measured gasvolumetrically by the Scheibler method (ISO 10693, 1995). The difference between total carbon and inorganic carbon is expressed as organic carbon $\left(\mathrm{C}_{\mathrm{org}}\right)$. Electrical conductivity (EC) was measured in a stirred water suspension made of $4 \mathrm{~g}$ of soil in $20 \mathrm{ml}$ distilled water (conductivity 0.9$1.0 \mu \mathrm{S} \mathrm{cm}^{-1}$ ) using a WTW Conductometer LF 191 (Weitheim, Germany). Soil aggregate stability (SAS) was determined according to DIN Norm 19683-16 (1998).

The clay mineralogical composition was analyzed with a Phillips PW 1710 X-ray diffractometer with $\mathrm{Cu}-\mathrm{K} \alpha$ radiation (Table 2). For cation saturation of the clay minerals, $40 \mathrm{ml}$ of the clay suspension was mixed with $10 \mathrm{ml}$ of $4 \mathrm{~N}$ $\mathrm{KCl}$ solution and $4 \mathrm{~N}$ of $\mathrm{MgCl}_{2}$ solution, respectively, and shaken for $12 \mathrm{~h}$. The clay mineral analysis is described in more detail in Terhorst et al. (2012).

The soil samples were suspended in distilled water, sonicated and analyzed by Micromeritics SediGraph 5000 ET (Micromeritics Instrument Corporation, Norcross, GA, USA) in combination with wet sieving. The fraction $2000-$ $63 \mu \mathrm{m}$ was wet-sieved, the fraction $63-2 \mu \mathrm{m}$ was analyzed by sedimentation and $\mathrm{X}$-ray attenuation.

The ultrasonic dispersion equipment used was an adapted ultrasonic fatigue testing equipment (Mayer, 2006). A titanium alloy probe was inserted into the soil-water mixture and performed resonance vibrations at $19.1 \mathrm{kHz}$. The ultrasonic probe had a cylindrical shape and a circular cross section (Ø $30 \mathrm{~mm})$. The vibration amplitude was controlled and kept constant with very high accuracy in a closed-loop electronic circuit. Deviation of pre-selected and actual vibration amplitude was maximum $\pm 1 \%$. For a detailed description of the equipment, including the calibration procedure to determine the power of the ultrasonic equipment, refer to Schomakers et al. (2011). 
Four grams of air-dried soil were placed in an aluminium beaker (Ø $44 \mathrm{~mm}$ ), $80 \mathrm{~cm}^{-3}$ of de-ionized water were added and the suspension was subsequently sonicated. To obtain a homogeneous distribution, the soil water suspension was gently stirred with a magnetic device $(2 \mathrm{~Hz}$, cylindrical shape with length of $25 \mathrm{~mm}$ and thickness of $8 \mathrm{~mm}$ ), immediately prior to and during the experiment. A copper tube was wound around the aluminium beaker and a peristaltic pump pumped water $\left(11^{\circ} \mathrm{C}\right)$ through the tube to limit temperature increase of the soil-water suspension during sonication. That way the suspension temperature was kept below $30^{\circ} \mathrm{C}$ throughout the ultrasonic experiments.

Five treatments were chosen. The lowest specific energy of $0.5 \mathrm{~J} \mathrm{~cm}^{-3}$ was applied at a vibration amplitude of $0.5 \mu \mathrm{m}$. This amplitude is below the cavitation threshold of $0.6-0.7 \mu \mathrm{m}$ required for cavitation of gas-saturated deionized water (Schomakers et al., 2011). The highest specific energy applied was $500 \mathrm{~J} \mathrm{~cm}^{-3}$. According to Schmidt et al. (1999) this is sufficient to expect complete dispersion of soil samples. In detail, the treatments were as follows, a sonication time of:

1. $60 \mathrm{~s}$ at vibration amplitude $0.5 \mu \mathrm{m}$ : with the ultrasonic power of $0.7 \mathrm{~W}$, the ultrasonic energy absorbed in $80 \mathrm{~cm}^{-3}$ was $0.5 \mathrm{~J} \mathrm{~cm}^{-3}$;

2. $60 \mathrm{~s}$ at $2 \mu \mathrm{m}$ : with the ultrasonic power of $8.9 \mathrm{~W}$ $\left(6.7 \mathrm{~J} \mathrm{~cm}^{-3}\right)$;

3. $300 \mathrm{~s}$ at $5 \mu \mathrm{m}$ : with the ultrasonic power of $26.8 \mathrm{~W}$ $\left(100 \mathrm{~J} \mathrm{~cm}^{-3}\right)$;

4. $25 \mathrm{~min}$ at $5 \mu \mathrm{m}$ : with the ultrasonic power of $26.8 \mathrm{~W}$ $\left(500 \mathrm{~J} \mathrm{~cm}^{-3}\right)$;

and

5. a set of samples was treated with $\mathrm{H}_{2} \mathrm{O}_{2}$ and $0.1 \%$ dispersant solution, and then suspended in $80 \mathrm{~cm}^{3}$ distilled water and subsequently sonicated with $500 \mathrm{~J} \mathrm{~cm}^{-3}$.

After sonication, the suspension was sieved through a $200 \mu \mathrm{m}$ mesh and allowed to settle for $24 \mathrm{~h}$, after which all particles larger than $1.1 \mu \mathrm{m}$ had settled from the surface of the suspension, based on equation:

$$
d=k \sqrt{\frac{s}{t}}
$$

where: $d$ is particle diameter, $t$ is time, $s$ the distance which the particles move during sedimentation and $k$ is a constant depending exclusively on fluid characteristics (dynamic viscosity and density) and particle density.

Wartel et al. (1995) considered aggregation of particles after a prolonged period of rest but found not much difference in the silt and clay fraction between a period of rest of one hour and of $24 \mathrm{~h}$. Subsequently, the supernatant was pipetted to reduce the soil to water ratio, transferred to a porcelain cup, dried at $105^{\circ} \mathrm{C}$ and weighed. Accordingly, the cumulative curve obtained in the sedigraph was corrected by the amount of soil removed by the pipette.
The remaining suspension (about $30 \mathrm{ml}$ ) was stirred and transferred to the sedigraph cell.

The Sedigraph 5000 ET determines particle size distribution based on Stokes law (Stokes, 1851): a particle falling under its own weight in a liquid will reach a terminal (settling) velocity when the gravitational force balances the buoyancy and drag forces on the particle. Sedimentation techniques calculate the grain-size in terms of an equivalent sedimentation diameter $i e$ the diameter of a sphere settling with the same velocity as that of the particle. The physical theory of the sedimentation process has been described in Andrenelli et al. (2013).

During sedimentation in the instrument cell, the X-ray attenuation is measured with automatic recording of a cumulative curve showing percentage mass (of the $<63 \mu \mathrm{m}$ fraction) versus the logarithm of equivalent diameter. A particle density of $2.65 \mathrm{~g} \mathrm{~cm}^{-3}$ was assumed as it is often used with Stokes law in its application to soils and sediments (Andrenelli et al., 2013; Vdović et al., 2010) since the real density is unknown. Leifeld and Kögel-Knabner (2003) highlighted the shortcomings involved in choosing such a density. For our study the soil/water ratio was optimized to exclude hindered settling and flocculation. In addition, the soils displayed low SOM content (Table 1) and similar mineralogy (Table 2), which favoured the assumption. The temperature inside the sedigraph cell did not exceed $25^{\circ} \mathrm{C}$. It was maintained with a cooling device. The Reynolds number was kept $<0.3$ indicating laminar flow. The time for a single analysis from 63 to $1 \mu \mathrm{m}$ was about $25 \mathrm{~min}$.

A separate analysis with sieves was done. Treatments 1 to 5 were repeated. Immediately after sonication, the soil-water suspension was transferred to a sieving tower (Fritsch Analysette 3 Pro) with vibration amplitude set at $0.1 \mu \mathrm{m}$ and frequency at $50 \mathrm{~Hz}$. Two standardized sieves of apertures 250 and $63 \mu \mathrm{m}$ were used. Sieving lasted $60 \mathrm{~s}$ with $700 \mathrm{ml}$ water. The remaining fractions were transferred to porcelain cups, placed in an oven and dried at $105^{\circ} \mathrm{C}$ for $24 \mathrm{~h}$. The final mass fraction was determined with an accuracy of $0.001 \mathrm{~g}$. The respective calculated mean amount of the sieved fraction $<63 \mu \mathrm{m}$ was set as baseline value for the sedimentation ie representing $100 \%$ mass on the sedigraph recording sheet. The sieve size distributions $>250$ and $>63 \mu \mathrm{m}$ were afterwards added to the sedigraph cumulative curve.

IBM SPSS Statistics 21 was used to calculate means, standard deviations and mean coefficients of variation. Duncan Test was used for comparison of means with probability level of $\mathrm{p}<0.05$.

\section{RESULTS}

The loamy sand Cambisol (Fig. 1a) displayed a high amount $(75 \pm 2.4 \%)$ of soil fraction $>63 \mu \mathrm{m}$ at $0.5 \mathrm{~J} \mathrm{~cm}^{-3}$. With increasing specific energy, there was an overall decrease in the $2000-250 \mu \mathrm{m}$ and the $250-63 \mu \mathrm{m}$ fractions 
a

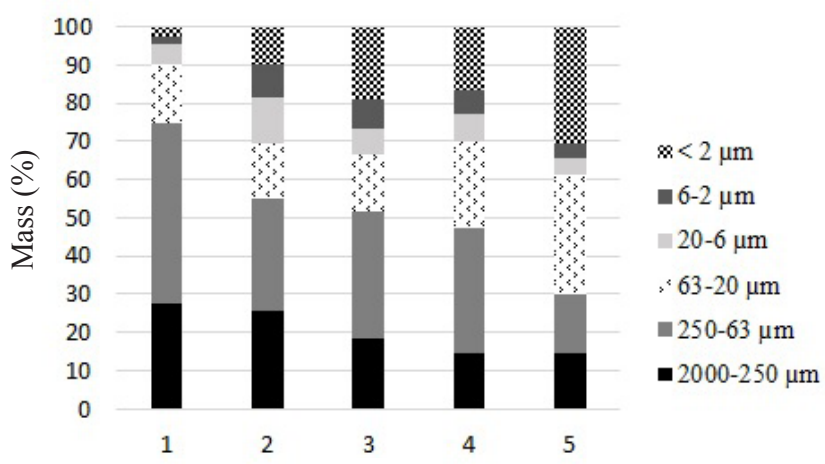

b

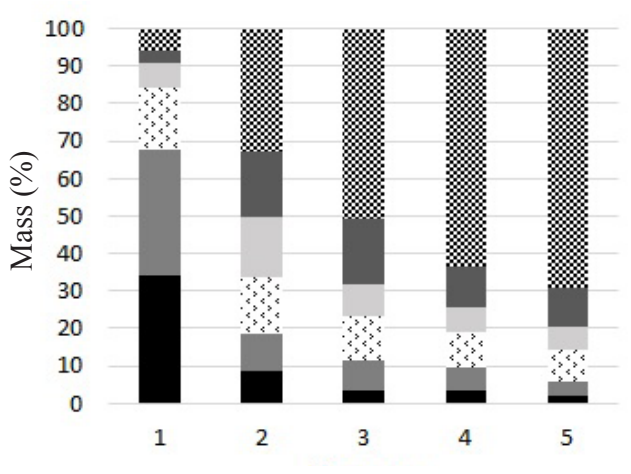

$\mathrm{c}$

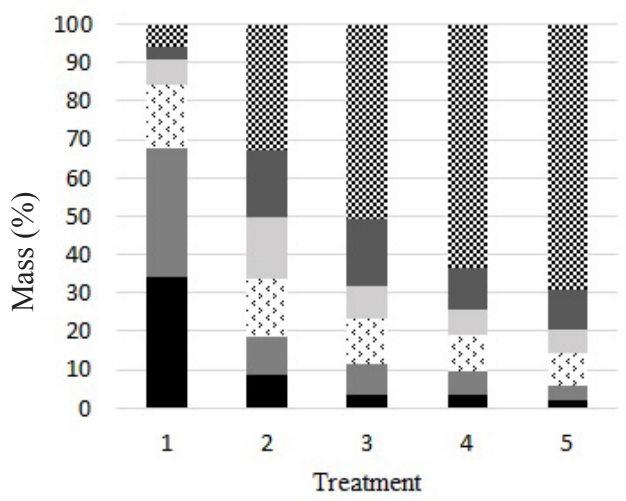

Fig. 1. Percentage of soil fraction of: a - loamy sand Cambisol, b - clay sand Cambisol, and c - silt loam Chernozem after treatment $1-0.5,2-6.7,3-100,4-500$, and $5-500 \mathrm{~J} \mathrm{~cm}^{-3}$ with chemical pre-treatment. and a gain in the 63-20 and $<2 \mu \mathrm{m}$ fractions. The fraction of $20-63 \mu \mathrm{m}$ increased with increasing energy levels and with the destruction of organic matter. All cumulative curves of the loamy sand Cambisol displayed a similar shape (Fig. 2a). The differences between 6.7, 100 and $500 \mathrm{~J} \mathrm{~cm}^{-3}$ were less pronounced, compared to the difference in the low specific energy range, ie $0.5 \mathrm{~J} \mathrm{~cm}^{-3}$ and $6.7 \mathrm{~J} \mathrm{~cm}^{-3}$. When treated chemically (treatment 5), fraction 250-63 $\mu \mathrm{m}$ and fraction 20-2 $\mu \mathrm{m}$ lost half of their mass to fraction 63-20 $\mu \mathrm{m}$ and fraction $<2 \mu \mathrm{m}$, respectively; fraction 2000-250 $\mu \mathrm{m}$ did not change notably.

The clay loam Cambisol ie site b (Fig. 1b), showed a high amount of stable aggregates $>63 \mu \mathrm{m}$ at $0.5 \mathrm{~J} \mathrm{~cm}^{-3}$. The increase in specific energy from 0.5 to $6.7 \mathrm{~J} \mathrm{~cm}^{-3} \mathrm{re}-$ duced the soil fraction $2000-63 \mu \mathrm{m}$ from $68 \pm 1.9 \%$ to $19 \pm 1.7 \%$. At and above $6.7 \mathrm{~J} \mathrm{~cm}^{-3}$, the cumulative curves of the clay loam Cambisol changed in shape, from concave to convex (Fig. 2b). Treatments 2 to 5 showed curve resemblance. The fraction $>63 \mu \mathrm{m}$ continued to lose mass through the dispersion of aggregates and most notably there was a simultaneous steady increase of the $<2 \mu \mathrm{m}$ fraction. All fractions $>2 \mu \mathrm{m}$ changed when treated chemically: fraction 2000-63 $\mu \mathrm{m}$ lost, fraction 63-2 $\mu \mathrm{m}$ gained mass.

Similar to site b, the Chernozem (Fig. 1c) showed a high amount of fraction $>63 \mu \mathrm{m}$ at $0.5 \mathrm{~J} \mathrm{~cm}^{-3}, 63 \%$ $( \pm 3.4 \%)$, but the fraction mostly consisted of aggregates and particles of the fine sand fraction. That fraction showed a notable decline between $0.5 \mathrm{~J} \mathrm{~cm}^{-3}$ and $6.7 \mathrm{~J} \mathrm{~cm}^{-3}$ and the aggregates continued to disperse with increasing specific energy. The mass lost was mainly gained in the $63-20 \mu \mathrm{m}$ and the $<2 \mu \mathrm{m}$ fractions. All five cumulative curves of the Chernozem (Fig. 2c) displayed a similar increase in small particle fractions. Differences between the particle size distributions of chemically and ultrasonically treated samples (treatment $5 \mathrm{vs}$. treatment 4 ) were small for site c, the most notable change being observed for fraction 2000-63 $\mu \mathrm{m}$.

Treatment 1 and 2 at the low energy range of 0.5 and $6.7 \mathrm{~J} \mathrm{~cm}^{-3}$, respectively, showed the most pronounced differences to each other. Differences between the particle size distributions of chemically and ultrasonically treated samples were identifiable, most notably for site a, the loamy sand Cambisol. Sonication at $500 \mathrm{~J} \mathrm{~cm}^{-3}$ resulted in an incomplete disintegration of aggregates for all soil samples if the percentage-clay value obtained by the standard procedure involving the Köhn-pipette is used as a basis for comparison (Table 1). It should be recognized, however, that the degree of dispersion reported may reflect subsequent flocculation of clay particles (Christensen, 1992). However, in our experiments, flocculation was not observed. Also, Edwards and Bremner (1967a), using up to 120 min of vibration, showed that suspensions obtained by ultrasonic treatment of soils exhibit remarkable stability and show no tendency to flocculate for days. 


\section{DISCUSSION}

The specific energy levels applied significantly altered the size distribution of soil aggregates and particles. Figure 2 indicate a gradual breakdown of soil aggregates with an increase in energy, supporting the aggregate hierarchy theory (Tisdall and Oades, 1982). In addition, the investigated soils were 2:1 clay-dominated soils (Table 2) where SOM is expected to be the primary binding agent because polyvalent-organic matter complexes form bridges between the negatively charged clay platelets (Six et al., 2000).

Our measurements showed gradual aggregate breakdown with satisfactory reproducibility, thus supporting Six et al. (2004) suggestion to view aggregates as dynamic rather than static entities.

a

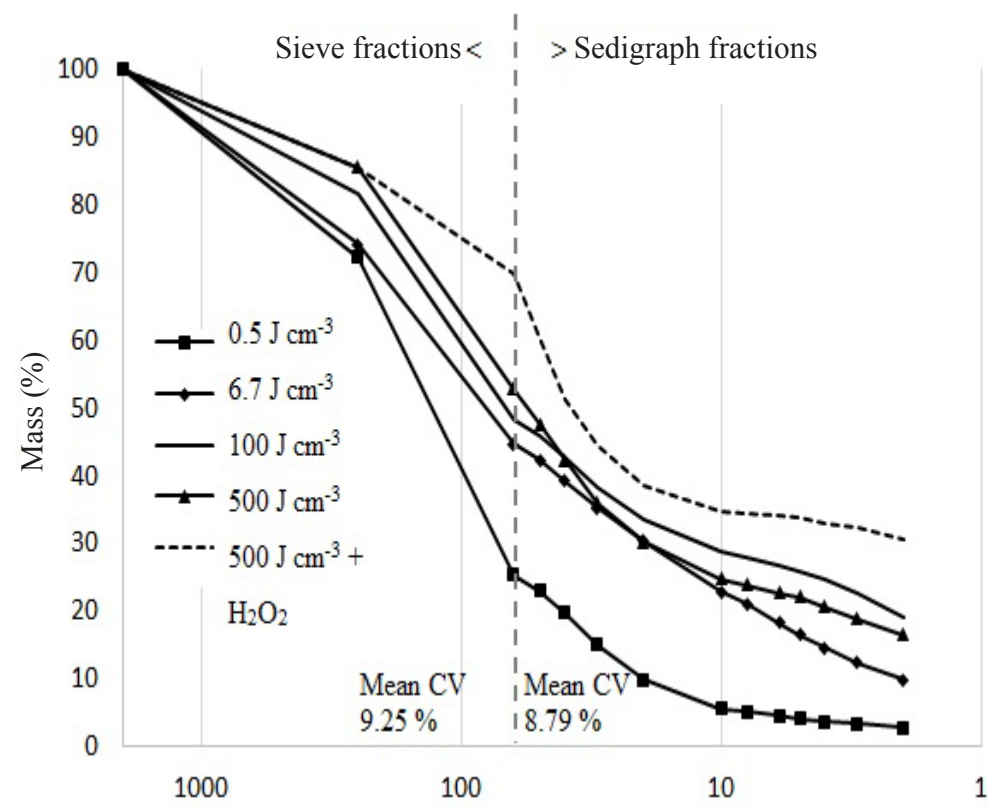

b

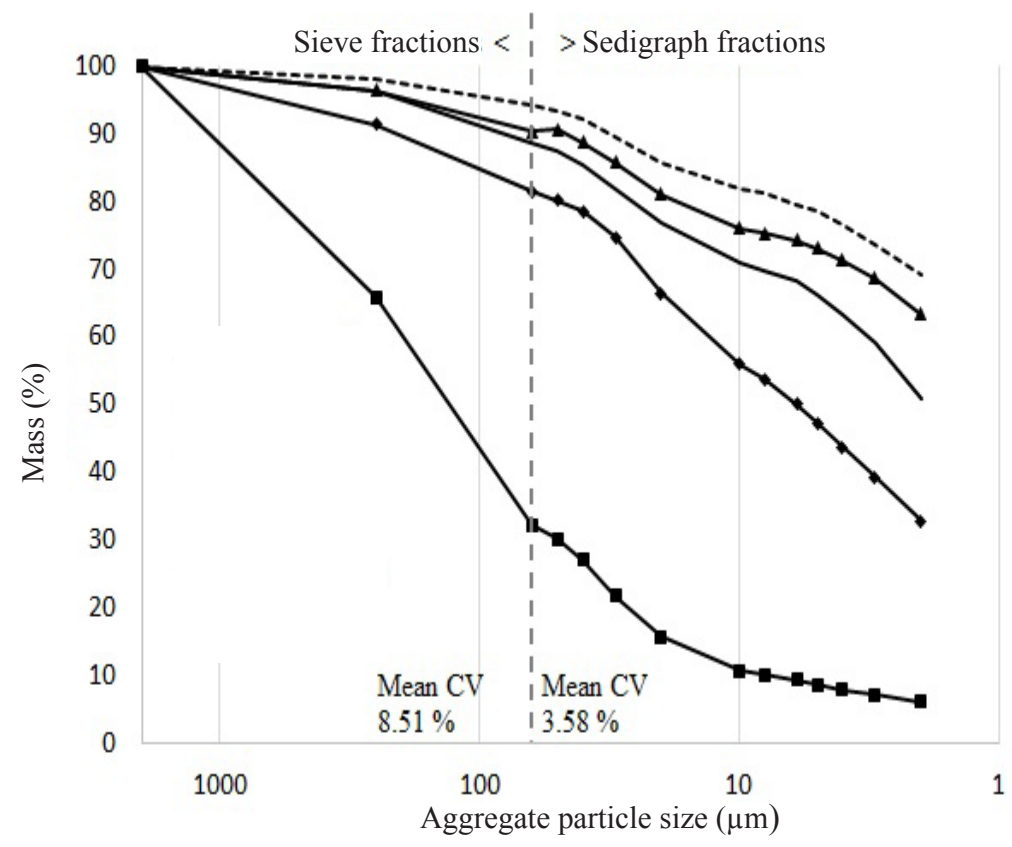

Fig. 2. Aggregate particle size distribution of soil samples from: a - loamy sand Cambisol (site a), b - clay sand Cambisol (site b), and $\mathrm{c}-$ silt loam Chernozem (site c) dispersed by ultrasonication and chemical pre-treatment (dashed line). Mean coefficients of variation $(\mathrm{CV})$ are given for the sieve and the sedimentation fractions, respectively. 


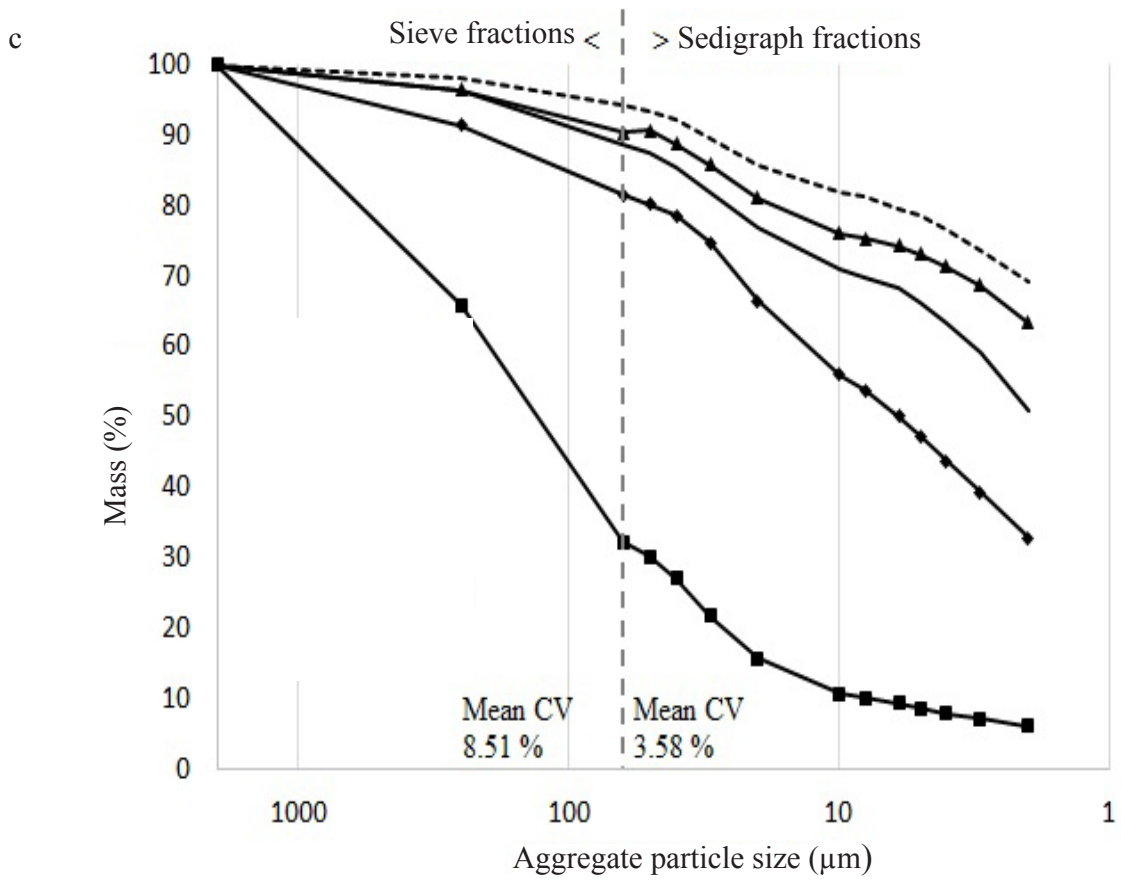

Fig. 2. Continuation.

Our study focused on low ultrasonic energies and showed that considerable dispersion and re-distribution of aggregates already took place at levels $<10 \mathrm{~J} \mathrm{~cm}^{-3}$ where the chances of damaging particles or organic matter fractions can be expected to be rather small. Also, our implemented procedure might reduce cavitation-caused chemical reactions which bear the potential to change chemical characteristics of organic compounds ie to alter the ratio between water dissolved hydrophobic and hydrophilic organic compounds (Kaiser and Asefaw Berhe, 2014). This has important bearings on the study of soil organic matter binding. Low ultrasonic energies are required to study the stability and breakdown dynamics of soil aggregates and the associated release of soil organic matter.

In our study, differences between chemical and ultrasonic treatment did occur to a variable extent. Vdović et al. (2010) compared different methods and sample pre-treatment for particle size distribution of soils, and observed in their study that the oxidising agent $\mathrm{H}_{2} \mathrm{O}_{2}$, which was also used in our study, appeared to be effective in increasing the clay content through disruption of aggregates bound with organic material. This can explain the increase in clay content for sites a and $\mathrm{b}$. Depending on the soil, different fractions did change, demonstrating that $500 \mathrm{~J} \mathrm{~cm}^{-3}$ without additional chemical treatment was not enough energy to disperse the soils completely, not even the macroaggregate fractions $2000-63 \mu \mathrm{m}$ as propozed by Leifeld and KögelKnabner (2003). This indicates that the macroaggregates of the no-tillage soils in our study were probably stabilized by organic matter and iron oxides (Pronk et al., 2011).
If the objective is only to determine the particle size distribution of a soil, the traditional sodium hexametaphosphate dispersion and sedimentation method would be preferred because of economy of time and less investment costs (Yang et al., 2009). But as the sodium hexametaphosphate dispersing agent may change the quality of soil organic matter (Ladd et al., 1993), the sonication method is required if organic matter associated with the particle fractions is to be characterized.

Comparing the ultrasonic power, the same power $(26.8 \mathrm{~W})$ was used in treatment 3 and 4 . The duration of the ultrasonic treatment was five times longer in treatment 4 and, consequently, the applied energy was increased by the same factor. Poeplau and Don (2014) argued that the power setting of an ultrasonic device rather than the energy influences the distribution of soil mass, soil organic carbon content and quality in different size fractions. This may serve to explain the relatively small difference in soil mass distributions for site a and site $b$ when comparing treatments 3 and 4 .

The X-ray attenuation technique, following ultrasonic dispersion, resulted in a higher content of fine particles and a lower content of the sand fraction compared to the values gained from the combined sieve and pipette method presented in Table 1. Watts et al. (2000) point out that sedimentation techniques could systematically be biased towards finer particles. This effect arises from the departure of particle shape and density from those used in the application of Stokes law, the neglect of particle diffusion and convective disturbances, so that all solids remaining in suspension at the end of the prescribed settling period are included within the smallest size (Vdović et al., 2010). 


\section{CONCLUSIONS}

1. Aggregate stability proved to be a dynamic parameter with gradual breakdown upon increase in disruptive energy.

2. The sedimentation/X-ray attenuation method following ultrasonic dispersion allows to study the breakdown and redistribution of soil aggregates at higher resolution compared to the conventional sieving method.

3. The strongest effects were observed in the range of low specific energies $\left(<10 \mathrm{~J} \mathrm{~cm}^{-3}\right)$. It is therefore recommended to apply low ultrasonic energies to soil-water suspensions for more refined studies of soil organic matter binding within aggregates.

\section{ACKNOWLEDGEMENTS}

We acknowledge the physical science expertise provided by Harald Rennhofer (University of Natural Resources and Life Sciences, Institute of Physics and Material Sciences, Vienna).

\section{REFERENCES}

Amelung W. and Zech W., 1999. Minimisation of organic matter disruption during particle-size fractionation of grassland epipedons. Geoderma, 92(1-2), 73-85.

Andrenelli M.C., Fiori V. and Pellegrini S., 2013. Soil particlesize analysis up to $250 \mu \mathrm{m}$ by X-ray granulometer: Device set-up and: Regressions for data conversion into pipetteequivalent values. Geoderma, 192(1), 380-393.

Balesdent J., Pétraud J.P., and Feller C., 1991. Effets des ultrasons sur la distribution granulométrique des matières organiques des sols. Science du Sol, 29, 95-106.

Bryan R.B., 1971. The efficiency of aggregation indices in the comparison of some English and Canadian soils. J. Soil Sci., 22(2), 166-178.

Buchan G., Grewal K., Claydon J., and Mcpherson R., 1993. A comparison of sedigraph and pipette methods for soil particle-size analysis. Soil Res., 31(4), 407-417.

Chenu C. and Plante A.T., 2006. Clay-sized organo-mineral complexes in a cultivation chronosequence: Revisiting the concept of the 'primary organo-mineral complex'. Eur. J. Soil Sci., 57(4), 596-607.

Christensen B.T., 1992. Physical Fractionation of Soil and Organic Matter in Primary Particle Size and Density Separates. Advances in Soil Science (Ed. B.A. Stewart). New York, Springer-Verlag.

DIN Norm 19683-16, 1998. Determination of aggregate stability using the method of wet sieving. Soil quality laboratory tests - Part 16. Berlin.

Edwards A.P. and Bremner J.M., 1967a. Dispersion of soil particles by sonic vibration. J. Soil Sci., 18(1), 47-63.

Edwards A.P. and Bremner J.M., 1967b. Microaggregates in soils. J. Soil Sci., 18, 64-73.

Gerzabek M.H., 1992. Determination of Soil Texture Using the Sedi-Graph 5100 and MasterTech Automatic Sampler. The microREPORT 3: 1-2.
Goossens D., 2008. Techniques to measure grain-size distributions of loamy sediments: A comparative study of ten instruments for wet analysis. Sedimentology, 55(1), 65-96.

ISO 10693, 1995. Soil Quality. Determination of carbonate content. Volumetric method.

ISO 10694, 2009. Soil quality. Determination of organic and total carbon after dry combustion (elementary analysis).

ISO 11277, 2009. Soil Quality. Determination of particle size distribution in mineral soil material. Method by sieving and sedimentation.

Kaiser M. and Asefaw Berhe A., 2014. How does sonication affect the mineral and organic constituents of soil aggregates? - A review. J. Plant Nutr. Soil Sci., 177(4), 479-495.

Kaiser M., Berhe A.A., Sommer M., and Kleber M., 2012. Application of ultrasound to disperse soil aggregates of high mechanical stability. J. Plant Nutr. Soil Sci., 175(4), 521-526.

Klik A., Trümper G., Baatar U., Strohmeier S., Liebhard P., Deim F., Moitzi G., Schüller M., Rampazzo N., Mentler A., Rampazzo-Todorovic G., Brauner E., Blum W., Köllensberger G., Hann S., Breuer G., Stürmer B., Frank S., Blatt J., Rosner J., Zwatz-Walter E., Bruckner R., Gruber J., Sopieß R., Sanitzer H., Haile T., Selim S., Grillitisch B., Altmann D., Guseck C., Bursch W. and Fürhacker M., 2010. Effects of Different Soil management Systems on Carbon Sequestration, $\mathrm{CO}_{2}$ Emissions and Behaviour of Glyphosate and AMPA in Soils. EDISSOC. Vienna, BMLFUW in cooperation with Lower Austria and Styria. Final report 100069GZ. BMLFUW-LE.1.3.2/0130II/1/2006: 299.

Ladd J.N., Foster R.C., and Skjemstad J.O., 1993. Soil structure: carbon and nitrogen metabolism. Geoderma, 56(1-4), 401-434.

Leifeld J. and Kögel-Knabner I., 2003. Microaggregates in agricultural soils and their size distribution determined by X-ray attenuation. Eur. J. Soil Sci., 54(1), 167-174.

Mayer H., 2006. Ultrasonic torsion and tension-compression fatigue testing: Measuring principles and investigations on 2024-T351 aluminium alloy. Int. J. Fatigue., 28(11), 1446-1455.

Morgan R.P.C., 2005. Soil Erosion and Conservation. Oxford, Blackwell.

Poeplau C. and Don A., 2014. Effect of ultrasonic power on soil organic carbon fractions. J. Plant Nutr. Soil Sci., 177(2), 137-140.

Pronk G.J., Heister K., and Kögel-Knabner I., 2011. Iron oxides as major available interface component in loamy arable topsoils. Soil Sci. Soc. Am. J., 75(6), 2158-2168.

Raine S.R., 1998. Towards a fundamental understanding of soil aggregate breakdown under applied mechanical energies. Proc. Int. Conf. Eng. in Agriculture, September 27-30, Perth, Australia.

Schmidt M.W.I., Rumpel C., and Kögel-Knabner I., 1999. Evaluation of an ultrasonic dispersion procedure to isolate primary organomineral complexes from soils. Eur. J. Soil Sci., 50(1), 87-94.

Schomakers J., Mentler A., Steurer T., Klik A., and Mayer H., 2011. Characterization of soil aggregate stability using low intensity ultrasonic vibrations. Int. Agrophys., 25, 165-172.

Six J., Bossuyt H., Degryze S., and Denef K., 2004. A history of research on the link between (micro)aggregates, soil biota, and soil organic matter dynamics. Soil Till. Res., 79(1), 7-31. 
Six J., Paustian K., Elliott E.T., and Combrink C., 2000. Soil structure and organic matter: I. Distribution of aggregatesize classes and aggregate-associated carbon. Soil Sci. Soc. Am. J., 64(2), 681-689.

Stokes G.G., 1851. Transactions of the Cambridge Philosophical Society, 9, 8-27.

Terhorst B., Ottner F., and Wriessnig K., 2012. Weathering intensity and pedostratigraphy of the Middle to Upper Pleistocene loess/palaeosol sequence of Wels-Aschet (Upper Austria). Quatern Int., 265(0), 142-154.

Tisdall J.M. and Oades J.M., 1982. Organic matter and waterstable aggregates in soils. J. Soil Sci., 33(2), 141-163.

Vdović N., Obhodaš J., and Pikelj K., 2010. Revisiting the particle-size distribution of soils: Comparison of different methods and sample pre-treatments. Eur. J. Soil Sci., 61(6), 854-864.
Wartel S., Barusseau J.P., and Cornand L., 1995. Improvement of grain-size analysis using the automated SEDIGRAPH 5100. Brussels, Royal Belgian Institute of Natural Sciences, $80,28$.

Watts C.W., Whalley W.R., Bird N.R.A., and Ashman M.R., 2000. The effect of iron concentration, hindered settling, saturating cation and aggregate density of clays on the size distribution determined by gravitation X-ray sedimentometry. Eur. J. Soil Sci., 51(2), 305-311.

WRB, I. W. G., 2006. World reference base for soil resources 2006 - a framework for international classification, correlation and communication. World Reference Base for Soil Resources.

Yang X.M., Drury C.F., Reynolds W.D., and MacTavish D.C., 2009. Use of sonication to determine the size distributions of soil particles and organic matter. Can. J. Soil Sci., 89(4), 413-419. 